\title{
PENGEMBANGAN ALAT ROUND COUNT TIMER MENGGUNAKAN WIRELESS SENSOR UNTUK LATIHAN KEBUGARAN
}

\section{DEVELOPMENT OF ROUND COUNT TIMER TOOLS USING WIRELESS SENSOR FOR FITNESS TRAINING}

\section{Dicky Pranata, Muhamad Sazeli Rifki*, Endang Sepdanius, Windo Wiria Dinata}

Fakultas Ilmu Keolahragaan, Universitas Negeri Padang, Jl. Prof.Dr. Hamka Air Tawar Kota Padang, Sumatera Barat, Indonesia

\author{
*Corresponding Author: Muhamad Sazeli Rifki, msr_rifki@fik.unp.ac.id
}

Received: 2021-04-26; Revised: 2021-08-29; Accepted: 2021-09-10

\begin{abstract}
Abstrak
Penelitian ini bertujuan untuk mengembangkan alat Round Count Timer menggunakan Wireless sensor untuk latihan kebugaran dengan harapan dapat dijadikan sebagai evaluasi peningkatan dan penurunan tingkat kebugaran, maupun membantu kerja pelatih dalam pengambilan data kebugaran atlet. Jenis penelitian ini adalah penelitian pengembangan (Research and Development). Penelitian ini menggunakan validasi desain dari ahli yang berpengalaman dalam bidang tes dan pengukuran. Uji coba produk dengan skala kecil dilakukan pada 8 orang mahasiswa FIK UNP dan Uji coba pemakaian dilakukan pada 20 orang mahasiswa FIK UNP. Analisis data menggunakan statistik deskriptif. Hasil penelitian menunjukkan bahwa: (1) validitas ahli atletik dalam pengembangkan alat Round Count Timer menggunakan Wireless sensor untuk latihan berada pada kategori "Baik/Layak", (2) validitas ahli kepelatihan berada pada kategori "Baik/Layak", dan (3) uji coba produk kepada atlet atletik Sumatera Barat dan mahasiswa Fakultas Ilmu Keolahragaan berada pada kategori "Baik/Layak". Dengan kata lain, alat ini dapat direkomendasikan untuk mempermudah latihan kebugaran, evaluasi peningkatan dan penurunan tingkat kebugaran, serta membantu kerja pelatih dalam pengambilan data kebugaran atlet.
\end{abstract}

Kata Kunci : round count timer, wireless sensor, latihan kebugaran

\begin{abstract}
This study aims to develop a Round Count Timer using wireless sensors for fitness training with the hope that it can be used as an evaluation of the increase and decrease in fitness levels, as well as to help trainers work in collecting athlete fitness data. This type of research is research and development (Research and Development). This study uses design validation from experts who are experienced in the field of tests and measurements. Small-scale product trials were conducted on 8 FIK UNP students and use trials were carried out on 20 FIK UNP students. Data were analyzed using descriptive statistics. The results showed that: (1) the validity of athletic experts in developing the Round Count Timer tool using wireless sensors for fitness training in the "Good / Feasible" category, (2) the validity of the coaching experts in the "Good / Feasible" category, and (3) product trials for athletic athletes of West Sumatra and students of the Faculty of Sports Science obtained in the "Good / Eligible" category. In other words, this tool can be recommended to facilitate fitness training, evaluate the increase and decrease in fitness levels, and help trainers work in retrieving athlete fitness data.
\end{abstract}

Keyword: round count timer, wireless sensor, fitness training

How To Cite: Pranata,D., Rifki,M.S., Sepdanius,E.,Dinata, W.W. (2021). Pengembangan alat round count timer menggunakan wireless sensor untuk latihan kebugaran. Journal of Sport Education (JOPE), 4 (1), $19-29$. doi:http://dx.doi.org/10.31258/jope.4.1.19-29 


\section{PENDAHULUAN}

Olahraga sekarang telah menjadi aktivitas manusia yang tidak dapat dipisahkan dalam kelangsungan hidupnya. Olahraga tidak hanya sekedar pengisi waktu luang saja, melainkan sudah termasuk ke dalam kebutuhan manusia. Hal ini disebabkan karena olahraga banyak memberikan manfaat bagi orang yang melakukannya seperti, memperoleh kesehatan, kebugaran, kesenangan, meningkatkan status sosial, dan sebagai ajang pencapaian prestasi. "keolahragaan Nasional bertujuan memelihara dan meningkatkan kesehatan dan kebugaran, prestasi, kualitas manusia, menanamkan nilai moral dan akhlak mulia, sportifitas, disiplin, mempererat dan membina persatuan dan kesatuan bangsa, memperkokoh ketahanan Nasional, serta mengangkat harkat dan martabat kehormatan bangsa (Undang-Undang Republik Indonesia Nomor 3 Tahun 2005 \& Peraturan Pemerintah Republik Indonesia. Sistem Keolahragaan Nasional, 2007).

Berdasarkan uraian tersebut, pengembangan olahraga harus digalakkan dengan memasyarakatkan olahraga dan mengolahragakan masyarakat, sehingga kedudukan olahraga menjadi penting dalam kehidupan masyarakat dalam menghasilkan manusia yang berkualitas, sehat jasmani dan rohani, menanamkan nilai moral dan akhlak mulia serta produktifitas dalam menjalani aktifitas sehari-hari. Aspek tersebut harus dikembangkan dan ditanamkan sejak usia dini, khususnya dalam pencapaian prestasi olahraga.

Pencapaian prestasi dalam olahraga memerlukan proses pembinaan yang terencana, berjenjang dan berkelanjutan. Dalam pencapaian prestasi yang maksimal terdapat banyak faktor yang mempengaruhi, secara garis besar dapat dikelompokkan menjadi faktor internal dan faktor eksternal. Pencapaian prestasi terbaik atlet ditentukan dan dipengaruhi oleh banyak faktor yang secara garis besar dapat dikelompokkan atas dua faktor, yaitu faktor internal (dalam) dan faktor eksternal (luar)". Faktor internal adalah faktor yang berasal dari dalam, yaitu dari diri atlet itu sendiri dengan segala potensi yang dimilikinya, seperti kemampuan fisik, teknik, taktik, dan kemampuan mentalnya. Sedangkan yang dimaksud dengan faktor eksternal adalah faktor yang mempengaruhi prestasi atlet yang berasal dari luar diri atlet, atau dari luar potensi yang dimiliki atlet seperti, faktor pelatih, pembina, iklim dan cuaca, gizi, sarana dan prasarana, organisasi, penonton, wasit, hakim garis, keluarga, dan lain sebagainya (Syafruddin, 2011).

Di samping beberapa faktor yang mempengaruhi prestasi atlet, sentuhan ilmu pengetahuan dan teknologi yang diterapkan juga merupakan faktor yang tidak kalah penting dalam meningkatkan kualitas atlet untuk mencapai prestasi. Pembinaan dan pengembangan olahraga prestasi sebagaimana yang dimaksud ayat (1) dan ayat (2) dilakukan oleh pelatih yang memiliki kualifikasi dan sertifikat kompetensi yang dapat dibantu oleh tenaga keolahragaan dengan pendekatan ilmu pengetahuan dan teknologi (Undang-Undang Republik Indonesia Nomor 3 Tahun 2005 \& Peraturan Pemerintah Republik Indonesia. Sistem Keolahragaan Nasional, 2007). Inovasi-inovasi yang dihasilkan dari kemajuan IPTEK meliputi hampir semua aspek kehidupan salah satunya adalah olahraga (Anggita et al., 2020).

Salah satu implementasi yang dilakukan dalam pemanfaatan teknologi dalam olahraga adalah yang berhubungan dengan pengukuran atau mengenai instrumen sebagai alat ukur. Tes adalah instrumen atau alat yang digunakan untuk memperoleh informasi tentang individu atau objek. Sebagai alat pengumpul informasi atau data, tes harus di rancang secara khusus. Salah satu hal yang harus dirancang dalam sebuah instrumen atau tes adalah pemaknaan data yang diperoleh melalui interpretasi skor yang dihasilkan harus tepat, bermanfaat dan dapat digunakan dalam kondisi saat pengukuran dilaksanakan. Sedangkan pengukuran adalah proses pengumpulan data atau informasi yang dilakukan secara objektif, melalui kegiatan pengukuran segala program yang menyangkut perkembangan dalam bidang apa saja dapat di kontrol dan dievaluasi. Hasil pengukuran berupa kuantifikasi dari jarak, waktu, jumlah, dan ukuran sebagainya (Ismaryati, 2008). 
Khusus dalam hal tes dan pengukuran, pemanfaatan teknologi sangatlah dianjurkan dalam rangka meminimalisir kesalahan dalam pengambilan data sehingga data yang terkumpul memiliki tingkat validitas tinggi. Apabila sesuatu yang hendak di ukur tidak sesuai terhadap alat atau instrumen yang digunakan, maka dapat dipastikan bahwa data yang dikumpulkan tidak akan menjelaskan apa yang seharusnya dijelaskan. Dalam suatu penelitian, alat pengambilan data atau instrumen menentukan kualitas data yang dikumpulkan dan kualitas data menentukan kualitas penelitian (Sumadi, 2013). Hal ini dikarenakan salah satu peran dan fungsi data adalah sebagai bahan dalam pengambilan kesimpulan suatu penelitian.

Instrument yang valid berarti alat ukur yang digunakan untuk mendapatkan data (mengukur) itu valid. Valid berarti instrumen tersebut dapat digunakan untuk mengukur apa yang seharusnya di ukur (Sugiyono, 2011). Suatu instrumen akan lebih baik apabila dilakukan pengujian secara berulang-ulang untuk meningkatkan kualitas instrument berdasarkan nilai validitas dan reliabilitasnya (Hayati \& Lailatussaadah, 2016). Instrumen dikatakan valid saat dapat mengungkap data dari variabel secara tepat tidak menyimpang dari keadaan yang sebenarnya (Yusup, 2018). Apabila sesuatu yang hendak di ukur tidak sesuai terhadap alat atau instrumen yang digunakan, maka dapat dipastikan bahwa data yang dikumpulkan tidak akan menjelaskan apa yang seharusnya dijelaskan.

One of the implementations carried out in the use of technology in an effort to improve performance in sports is related to the measurement or regarding instruments as a measurement tool. Specifically regarding tests and measurements, the use of technology is highly recommended in order to minimize errors in data collection, so that the data collected has a high level of validity (Saputra \& Ihsan, 2020). Dapat disimpulkan, salah satu implementasi yang dilakukan dalam pemanfaatan teknologi dalam upaya meningkatkan kinerja dalam olahraga berkaitan dengan alat ukur atau mengenai instrumen sebagai alat ukur. Khusus mengenai pengujian dan pengukuran, penggunaan teknologi sangat disarankan guna meminimalisir kesalahan dalam pengumpulan data, sehingga data yang dikumpulkan memiliki tingkat validitas yang tinggi.

Kemajuan teknologi dalam olahraga akan menunjang kerja keras atlet dan pelatih dalam pencapaian prestasi yang ditentukan. Negara-negara maju saat ini telah banyak memanfaatkan teknologi sebagai penunjang prestasi atletnya. Contoh negara-negara maju yang sukses olahraganya dengan memanfaatkan ilmu pengetahuan dan teknologi seperti Amerika Serikat, Cina, Jepang, Jerman, dan negara lainnya (Giartama et al., 2020). Dengan kata lain, peningkatan dari kemampuan para atlet dapat dicapai lebih cepat dan lebih efisien dengan sentuhan dan perkembangan teknologi yang diterapkan, khususnya dalam melakukan latihan kebugaran fisik atlet. Hal ini tentunya tidak berlaku bagi atlet saja, namun juga bagi seseorang yang ingin mencapai derajat kesehatan dan kebugaran dalam melakukan olahraga.

Kebugaran fisik merupakan dasar dalam pencapaian prestasi, tanpa ditunjang kebugaran fisik yang baik sangat tidak memungkinkan bagi atlet mencapai prestasi yang diinginkan. Untuk mencapai kebugaran yang baik, atlet bisa melatihnya dengan beberapa kegiatan seperti lari, renang, senam, bersepeda dan sebagainya. Salah satu aktifitas yang sering dilakukan untuk latihan kebugaran dari beberapa kegiatan tersebut adalah lari. Lari disebut juga sebagai nonteknik atau aktifitas alami yang relatif sederhana. Setiap langkah lari terdiri dari satu fase menopang (Support Phase) dan fase melayang (Flight Phase). Semua langkah ini dapat dirinci menjadi fase topang depan dan fase dorong bagi kaki topang dan tahap ayunan depan dan tahap pemulihan bagi kaki yang bebas (Zafar Sidik, 2017).

Lari dipandang sebagai bentuk latihan kebugaran yang banyak dilakukan atlet dan bahkan insan olahraga. Realita yang terjadi banyaknya kesalahan yang dilakukan masyarakat maupun atlet dalam mencapai kebugaran fisik, seperti melakukan latihan kebugaran dengan waktu yang ditentukan, tanpa memikirkan sudah tercapai atau belumnya kebugaran fisik 
yang baik. Hal ini dikarenakan masih kurangnya pengetahuan tentang kebugaran fisik serta masih belum mengenal alat maupun teknologi yang tepat dalam membantu seseorang maupun atlet untuk mencapai kebugaran yang baik. Padahal seperti yang di ungkapkan oleh (Ngadiman, 2011) bahwa minimnya peralatan olahraga dan kurangnya fasilitas latihan yang berbasis teknologi akan sangat mempengaruhi pencapaian prestasi olahraga.

Di Indonesia sendiri perkembangan peralatan tes dan pengukuran lari masih belum berkembang, hal ini mungkin terjadi karena negara kita belum memiliki teknologi yang cukup canggih dan para pakar olahraga tidak berkolaborasi dengan pakar teknologi, sehingga yang terjadi adalah tidak ada pemecahan secara ilmiah untuk menganalisis berbagai permasalahan yang ada di olahraga. Selain itu permasalahan yang terjadi dalam pengukuran kecepatan lari saat ini masih mengunakan alat pengukur waku dan kecepatan manual yaitu dengan mengunakan stopwatch. Pengunaan stopwatch menjadi masalah dalam keakuratan data yang diambil karena adanya perbedaan selang waktu dalam penekanan tombol, sehingga dapat banyak menimbulkan kesalahan (human error) karena tingkat refleks dan kepekaan manusia berbeda-beda, sehingga Perlu adanya suatu sistem alat penentu waktu dan kecepatan pelari yang otomatis (Rahmat et al., 2016).

Berdasarkan realita tersebut, maka muncullah pemikiran-pemikiran penulis untuk mengembangkan alat yang dapat membantu dalam latihan kebugaran yaitu Round Count Timer menggunakan Wireless sensor yang nantinya dapat menjadi solusi dan membantu atau mempermudah masyarakat dan atlet untuk latihan kebugaran. Dalam pengembangan alat Round Count Timer menggunakan Wireless sensor sebagai salah satu komponen dalam alat untuk memudahkan penghitungan jarak dan waktu pada saat berlari, di dalam alat Round Count Timer ada juga Software dan Hardware untuk menjalankan program yaitu Wireless sensor sebagai komponen utama, Display (LCD) sebagai Monitoring jarak dan waktu, lalu aplikasi yang dijalankan oleh komputer atau laptop untuk mengkoneksikan program dengan Wireless sensor yang di pasang pada alat Round Count Timer.

Alat ini bertujuan untuk mempermudah latihan kebugaran fisik seseorang maupun atlet dalam pengambilan data dan mengefisienkan kerja saat berlari atau memudahkan penghitungan jarak dan waktu, sehingga mendapatkan hasil yang valid. Selain itu, teknologi pendukung latihan kebugaran fisik ini sangat dibutuhkan dalam latihan untuk mencapai tujuan yang telah ditentukan oleh seseorang maupun atlet dalam latihan kebugaran fisik, sehingga nantinya dapat menjadi solusi dan membantu masyarakat dan atlet dalam membantu untuk latihan kebugaran. (Nurkholis, 2017) berpendapat motivasi akan selalu terjaga jika atlet mampu menetapkan tujuannya.

\section{METODE}

Jenis penelitian adalah penelitian pengembangan (Research and development). Penelitian pengembangan adalah suatu proses yang digunakan untuk mengembangkan dan menvalidasi produk-produk yang dikembangkan (Gall, M. D., Gall, J. P., \& Borg, 2003). Metode penelitian dan pengembangan (research and development) adalah metode penelitian yang digunakan untuk menghasilkan produk tertentu dan menguji keefektifannya (Purnama, 2013). Penelitian dan pengembangan saat ini bukanlah hanya sebagai wacana, tetapi telah memberi warna baru dalam penelitian-penelitian pendidikan, dengan harapan, setiap hasil dari Penelitian dan Pengembangan akan memberikan sumbangan yang positip terhadap peningkatan kualitas pembelajaran di semua jenjang pendidikan yang ada (Yuberti, 2014). Adapun dalam penelitian ini terdiri dari tiga tahap, yaitu: (1) tahap pra pengembangan, (2) tahap pengembangan produk, (3) tahap validasi produk. Pada tahap Pra-pengembangan, dilakukan studi pendahuluan dengan melakukan survei dengan cara memberikan pertanyaan-pertanyaan kepada pelatih tentang kebugaran atlet, studi dokumentasi tentang kesulitan yang dihadapi oleh pelatih dalam mengumpulkan data kebugaran atlet atletik, studi 
dokumentasi tentang model latihan yang dilakukan atlit untuk mencapai prestasi yang maksimal serta alat bantu yang dapat mendukung pada saat proses latihan, studi pustaka tentang cara meningkatkan kebugaran atlet atletik pada nomor lari. Pada tahap pengembangan, dilakukan langkah merencanakan dan mengembangan produk awal ini dirumuskan arah pengembangan alat round count timer menggunakan wireless sensor untuk latihan kebugaran.

Tahap validasi produk dilakukan secara validasi isi dan validasi emperik terhadap instrumen kebugaran untuk atlet lari. Validasi dimaksud untuk memperoleh informasi tentang kelayakan instrumen yang telah disusun guna mengukur kebugaran atlet lari. Validasi isi dilakukan oleh tiga orang pakar, yaitu satu orang pakar atletik, dan dua pakar Teknik (akademisi). Uji coba dilakukan pada skala kecil yang dilakukan pada 8 orang mahasiswa FIK UNP dan Uji coba pemakaian dilakukan pada 20 orang mahasiswa FIK UNP. Adapun desain yang digunakan dalam penelitian sebagai berikut.
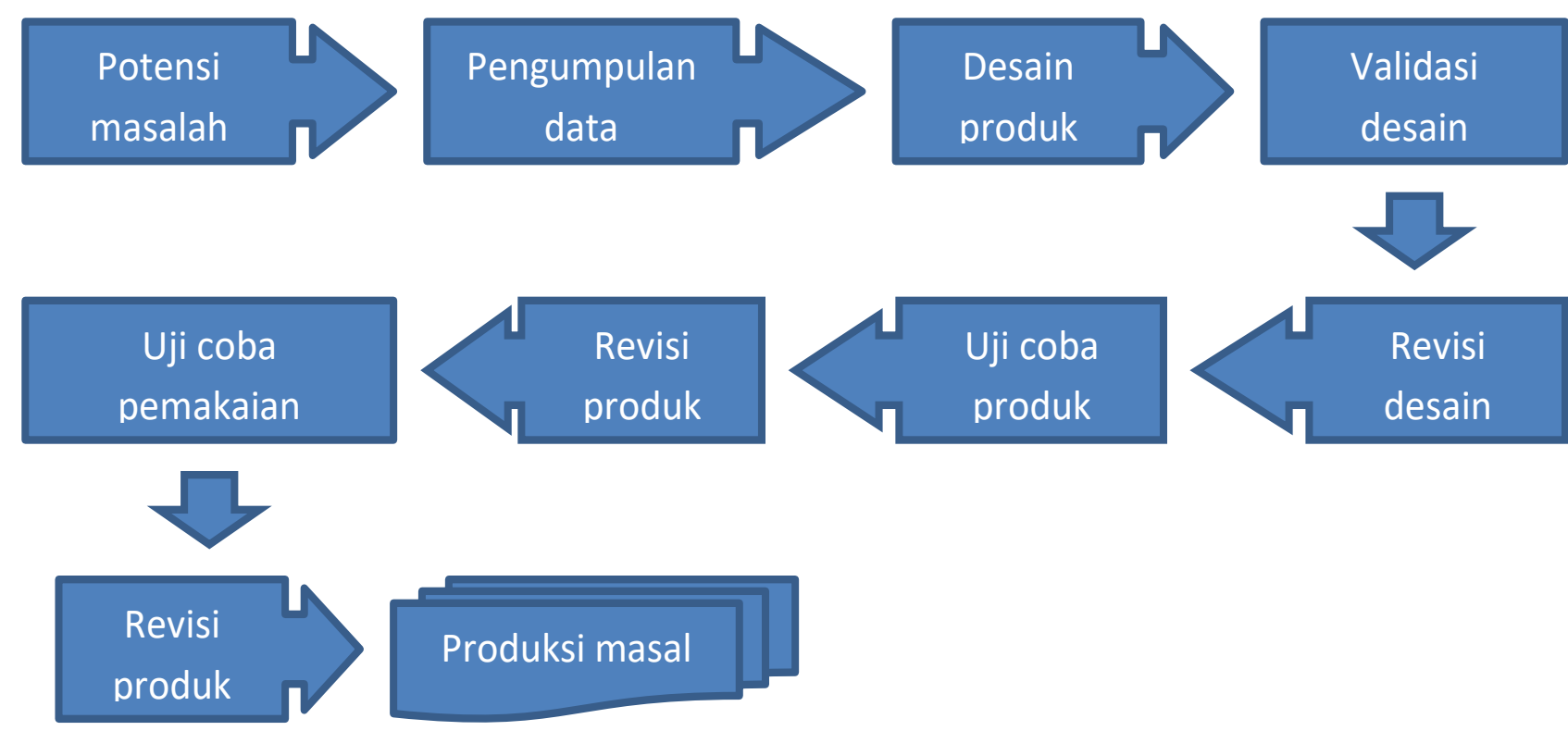

Gambar 1. Desain Langkah Penelitian

Data dan informasi yang telah dikumpulkan selanjutnya diolah dan dianalisis dengan menggunakan statistik deskriptif.

$$
p=\frac{f}{n} X 100 \%
$$

Dengan $p$ menunjukkan persentase, $f$ menunjukkan frekuensi dari setiap jawaban angket, $\mathrm{n}$ menunjukkan jumlah skor ideal, dan $100 \%$ menunjukkan kostanta. Untuk menentukan penafsiran terhadap hasil analisis persentase dapat digunakan kategori persentase kelayakan sebagai berikut:

Tabel 1. Kategori Persentase Kelayakan

\begin{tabular}{ccc}
\hline No & Skor Dalam Persentase & Kategori Kelayakan \\
\hline 1 & $<40 \%$ & Tidak Baik/Tidak Layak \\
2 & $40 \%-55 \%$ & Kurang Baik/Kurang Layak \\
3 & $56 \%-75 \%$ & Cukup Baik/Cukup Layak \\
4 & $76 \%-100 \%$ & Baik/Layak \\
\hline
\end{tabular}




\section{HASIL}

Alat Round Count Timer menggunakan Wireless sensor terdiri dari beberapa alat pendukung diantaranya Wireless sensor dengan jarak 1 kilometer dan aplikasi untuk menampilkan data yang di kirim dari Round Count Timer melalui Wireless yang dipasangkan pada alat Round Count Timer yang di dalam aplikasi tersebut menampilkan waktu per putaran, jumlah putaran, dan jumlah keseluruhan dari putaran yang dilakukan.

Tabel 2. Alat dan Cara menggunakan Round Count Timer

\section{Desain Perangkat Keras}

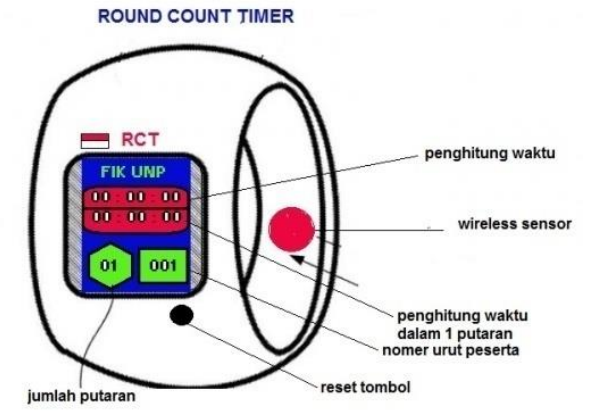

1. Testee dipasangkan alat berbentuk jam tangan dikoneksikan Wireless sensor yang dipasangkan dengan laptop/komputer untuk menjalankan program

2. Testee melakukan 1 (satu) kali putaran lapangan untuk menentukan jarak, bentuk, dan garis start Finish yang ditentukan, nantinya hasil ini akan langsung muncul di program yang ada di laptop/komputer.

3. Kemudian Testee berdiri di garis Start yang sudah ditentukan pada putaran pertama.

4. Saat Testee sudah berlari dalam satu putaran maka hasil akan muncul pada jam RCT dan laptop/komputer.

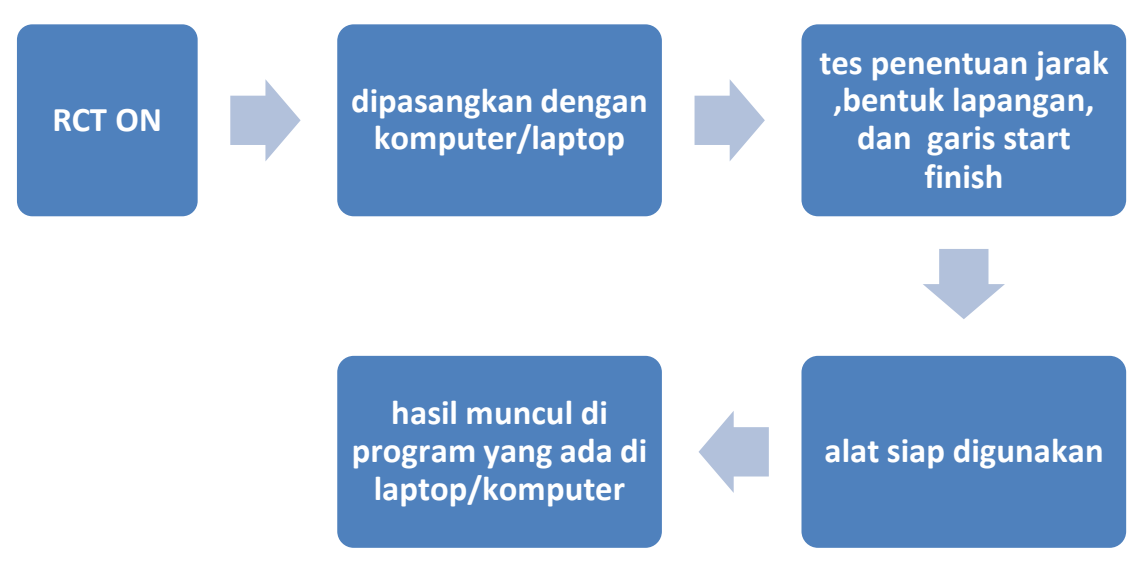

Gambar 2. Alur Penggunaan Perangkat Lunak

Untuk lebih jelasnya cara kerja Round Count Timer dapat dilihat pada gambar 3 berikut:

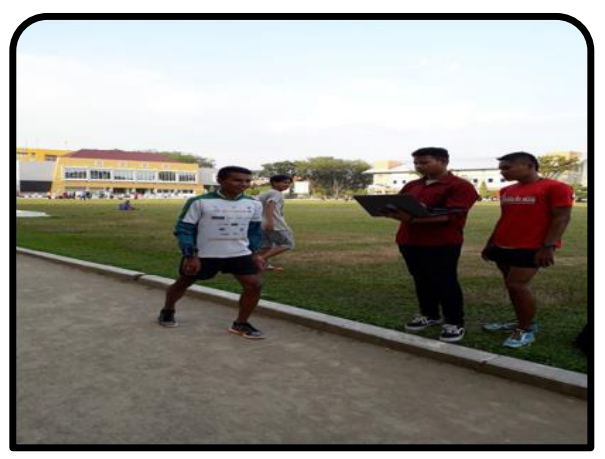

Alat Round Count Timer akan dipasangkan pada atlet untuk menentukan jarak yang diinginkan 


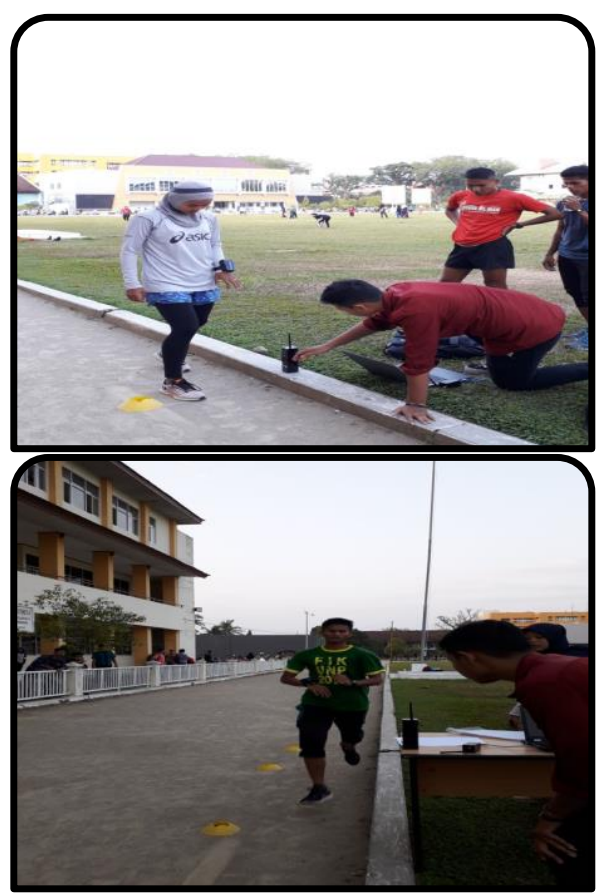

Setelah jarak yang diinginkan telah di dapatkan maka berikutnya pemasangan sensor pada garis Start untuk mengaktifkan penghitungan alat Round Count Timer

Gambar 3. Detail Alur Penggunaan Perangkat Lunak

Adapun hasil persentase penilaian pengembangan alat Round Count Timer oleh ahli sebagai berikut:

Tabel 3. Persentase Hasil Penilaian Pengembangan Alat Round Count Timer Oleh Ahli

\begin{tabular}{cccccc}
\hline No & Ahli & f & N & p (\%) & $\begin{array}{c}\text { Kategori } \\
\text { Kelayakan }\end{array}$ \\
\hline 1 & Atletik & 37 & 40 & $92,5 \%$ & Baik/Layak \\
2 & Kepelatihan & 33 & 40 & $82,5 \%$ & Baik/Layak \\
\hline
\end{tabular}

Untuk validitas ahli atletik didapat persentase penilaian sebesar 92,5\% atau dapat diartikan alat Round Count Timer menggunakan Wireless Sensor untuk latihan kebugaran "Baik/Layak" dan menurut ahli kepelatihan persentase penilaian sebesar $82,5 \%$ atau dapat diartikan alat Round Count Timer menggunakan Wireless Sensor untuk latihan kebugaran "Baik/Layak". Selanjutnya, uji coba produk pada mahasiswa FIK UNP yang berjumlah 20 orang sebagai berikut :

Tabel 4. Persentase Hasil Penilaian Pengembangan Alat Round Count Timer Atlet

\begin{tabular}{cccccc}
\hline No & Nama & f & N & p (\%) & Kategori Kelayakan \\
\hline 1 & ND & 38 & 40 & 95 & Baik/Layak \\
2 & DZ & 23 & 40 & 57,5 & Cukup Baik/Cukup Layak \\
3 & IF & 33 & 40 & 82,5 & Baik/Layak \\
4 & MY & 34 & 40 & 85 & Baik/Layak \\
5 & HD & 34 & 40 & 85 & Baik/Layak \\
6 & OY & 37 & 40 & 92,5 & Baik/Layak \\
7 & KH & 35 & 40 & 87,5 & Baik/Layak \\
8 & IA & 38 & 40 & 95 & Baik/Layak \\
9 & AD & 36 & 40 & 90 & Baik/Layak \\
10 & RGK & 32 & 40 & 80 & Baik/Layak \\
11 & IH & 37 & 40 & 92,5 & Baik/Layak \\
12 & SR & 34 & 40 & 85 & Baik/Layak \\
13 & WS & 32 & 40 & 80 & Baik/Layak \\
\hline
\end{tabular}


Journal Of Sport Education (JOPE), 4 (1) 2021 - 26

Dicky Pranata, Muhamad Sazeli Rifki*, Endang Sepdanius, Windo Wiria Dinata

Lanjutan Tabel 4. Persentase Hasil Penilaian Pengembangan Alat Round Count Timer Atlet

\begin{tabular}{cccccc}
\hline No & Nama & f & N & p (\%) & Kategori Kelayakan \\
\hline 14 & EK & 34 & 40 & 85 & Baik/Layak \\
15 & BP & 36 & 40 & 90 & Baik/Layak \\
16 & IM & 30 & 40 & 75 & Baik/Layak \\
17 & KK & 34 & 40 & 85 & Baik/Layak \\
18 & HF & 38 & 40 & 95 & Baik/Layak \\
19 & AM & 30 & 40 & 75 & Baik/Layak \\
20 & RFL & 38 & 40 & 95 & Baik/Layak \\
& Jumlah & 683 & 800 & 85,4 & Baik/Layak \\
\hline
\end{tabular}

Berdasarkan tabel 4, diperoleh penilaian dari hasil angket atlet atletik Sumatera Barat dan mahasiswa Fakultas Ilmu Keolahragaan sebesar 85,4\% atau dapat diartikan alat Round Count Timer menggunakan Wireless Sensor untuk latihan kebugaran "Baik/Layak".

\section{PEMBAHASAN}

Produk yang dikembangkan oleh peneliti berupa alat yang dapat membatu atlet dalam melakukan latihan kebugaran. Produk ini merupakan pengembangan alat Round Count Timer menggunakan Wireless sensor yang memiliki tujuan agar dapat mempermudah dalam penghitungan jarak dan waktu putaran yang efektif dan efisien dalam mengambil data saat latihan kebugaran serta meningkatkan kualitas kebugaran, mempermudah kerja pelatih, serta menjadikannya sebagai alat bantu latihan kebugaran yang efektif dan efisien. Hal ini tentu menjadi bahan perhatian sebab Kebugaran jasmani tentu sangat diperlukan oleh setiap manusia, terlebih oleh seorang atlet untuk memperoleh ketangkasan serta kekuatan melaksanakan program fisik guna mencapai prestasi yang maksimal (Puspitasari, P. W., Rizky, M. Y., \& Bekti, 2020). Wireless Sensor merupakan alat pendeteksi yang tersebar dan memiliki kemampuan untuk melingkupi area atau wilayah geografis tertentu yang disebut sebagai area sensor, dimana pada area sensor itu terdapat banyak sekali parameter - parameter yang dapat dideteksi (Imanningtyas et al., 2017). Teknologi komunikasi nirkabel seperti wireless sensor dapat dimanfaatkan untuk pemantauan terhadap parameter tertentu yang terdiri dari kumpulan sensor yang mengirimkan data melalui media gelombang radio (Puspitaningayu et al., 2018). Menurut (Dewi, 2011) Dengan teknologi wireless orang lebih mudah dalam berkomunikasi ataupun melakukan transfer data, tanpa perlu mengatur kabel-kabel untuk menghubungkan kedua perangkat.

Penelitian pengembangan ini merancang sebuah produk untuk membantu latihan kebugaran atlet maupun insan olahraga, produk tersebut berupa alat Round Count Timer menggunakan Wireless sensor. Untuk membuat alat ini, maka harus melalui proses penelitian dan pengembangan. setiap langkah penelitian R\&D harus dilaksanakan secara berurutan agar menghasilkan produk yang valid (Hanafi, 2017). Saat produk atau alat selesai, maka diperlukan validasi alat dari ahli dan uji coba atlet terhadap alat di lapangan. Pendekatan berbentuk IPTEK ini dilakukan agar para atlet lebih semangat dalam melakukan latihan (Jariono et al., 2020). Saat dilapangan, terlihat atlet bersemangat dan antusias tehadap alat Round Count Timer menggunakan Wireless sensor, sehingga atlet menjadi tertarik dan termotivasi setelah melihat alat yang belum pernah terpikirkan dengan konsep yang diberikan oleh peneliti. Selain itu, atlet menjadi tertarik untuk memilikinya setelah alat sudah bisa di produksi massal karena alat ini termasuk dalam kemajuan teknologi keolahragaan. (Syakur et al., 2017) berpendapat Perkembangan dan kemajuan teknologi olahraga sangat diperlukan demi kemajuan prestasi olahraga. Hal ini senada dengan pendapat (Santosa, 2016) Melalui pengembangan teknologi latihan yang tepat, diharapkan kualitas atlet (fisik, teknik, taktik dan mental) dapat meningkat sehingga prestasi maksimal. Pendapat diatas 
disempurnakan oleh pendapat (Permatasari et al., 2016) Negara yang melibatkan teknologi dalam pelaksanaan olahraga cenderung memiliki prestasi yang lebih maju, karena alat yang berteknologi tinggi memiliki tingkat keakuratan lebih tinggi dibandingkan alat manual. Adapun analisis kelebihan dan kelemahan alat Round Count Timer menggunakan Wireless sensor untuk latihan kebugaran sebagai berikut :

Tabel 5. Perbandingan Kelebihan dan Kelemahan Alat

\begin{tabular}{|c|c|c|}
\hline No & Kelebihan & Kelemahan \\
\hline 1 & $\begin{array}{l}\text { Alat Round Count Timer menggunakan } \\
\text { Wireless sensor untuk latihan kebugaran, } \\
\text { efektif dan efisien. }\end{array}$ & $\begin{array}{l}\text { Desain jam Round Count Timer yang } \\
\text { terlalu besar dan kurang nyaman dalam } \\
\text { pemakaian. }\end{array}$ \\
\hline 2 & $\begin{array}{l}\text { Atlet menjadi tertarik dan termotifasi } \\
\text { meningkatkan kebugaran. }\end{array}$ & $\begin{array}{l}\text { Gangguan sambungan saat banyaknya } \\
\text { Wireless yang ada di sekitar alat. }\end{array}$ \\
\hline 3 & $\begin{array}{l}\text { Dapat meningkatkan kualitas kebugaran } \\
\text { atlet maupun umum. }\end{array}$ & $\begin{array}{l}\text { Sensor yang masih kurang dalam } \\
\text { menentukan jarak. }\end{array}$ \\
\hline 4 & Dapat mempermudah kerja pelatih. & Belum adanya proteksi alat terhadap air. \\
\hline 5 & $\begin{array}{l}\text { Dapat menjadi salah satu alat yang bisa } \\
\text { digunakan dalam melakukan latihan } \\
\text { kebugaran, baik bagi atlet maupun } \\
\text { umum. }\end{array}$ & $\begin{array}{l}\text { Kemampuan } \\
\text { standar. }\end{array}$ \\
\hline 6 & $\begin{array}{l}\text { Sebagai evaluasi untuk meningkatkan } \\
\text { atau menurunnya kebugaran seseorang. }\end{array}$ & \\
\hline 7 & $\begin{array}{l}\text { Dapat menentukan intensitas latihan } \\
\text { kebugaran. }\end{array}$ & \\
\hline 8 & $\begin{array}{l}\text { Dapat mengenalkan penggunaan } \\
\text { teknologi dalam olahraga. }\end{array}$ & \\
\hline
\end{tabular}

\section{SIMPULAN}

Berdasarkan hasil penelitian yang telah dilakukan, bahwa alat Round Count Timer menggunakan Wireless sensor dapat direkomendasikan untuk mempermudah seseorang seperti pelatih maupun atlet dalam latihan kebugaran. Alat ini masih belum dikatakan sempurna karena masih terdapat berbagai kekurangan diantaranya Kemampuan program yang masih standar dan desain jam Round Count Timer yang terlalu besar dan kurang nyaman dalam pemakaian. Semoga pada penelitian selanjutnya alat ini bisa mendapat perbaikan dalam hal tampilan agar menjadi lebih menarik dan efisien kemudian juga bisa di uji cobakan pada jumlah sampel yang lebih banyak.

\section{REFERENSI}

Anggita, G. M., Ali, M. A., Sugiarto, S., \& Mukarromah, S. B. (2020). Erratum: analisis pengetahuan dan partisipasi siswa sekolah dasar terhadap permainan tradisional. JUARA : Jurnal Olahraga, 5(2), 0-6. https://doi.org/10.33222/juara.v5i2.913

Dewi, L. C. (2011). Wireless technology development: history, now, and then. ComTech: Computer, Mathematics and Engineering Applications, 2(2), 1224. https://doi.org/10.21512/comtech.v2i2.2936

Gall, M. D., Gall, J. P., \& Borg, W. R. (2003). Educational research: an introduction (7th ed.). In Boston, MA: A\& B Publications. 
Giartama, Destriani, Waluyo, \& Muslimin. (2020). Efektivitas alat tes servis bolavoli berbasis mikrokontroller. Jurnal Sportif: Jurnal Penelitian Pembelajaran, 6(2), 499-513.

Hanafi. (2017). Konsep penelitian r \& d dalam bidang pendidikan. Saintifika Islamica: Jurnal Kajian Keislaman, 4(2), 130.

Hayati, S., \& Lailatussaadah. (2016). Validitas dan reliabilitas instrumen. Jurnal Ilmiah DIDAKTA, 16(2), 169-179.

Imanningtyas, E., Akbar, S. R., \& Syauqy, D. (2017). Implementasi wireless sensor network pada pemantauan kondisi struktur bangunan menggunakan sensor accelerometer mma7361. Jurnal Pengembangan Teknologi Informasi Dan Ilmu Komputer (J-PTIIK) Universitas Brawijaya, 1(7), 545-554.

Ismaryati. (2008). Tes dan pengukuran olahraga. Surakarta : LPP UNS dan UNS Press.

Jariono, G., Nursubekti, N., Indarto, P., Hendarto, S., Nugroho, H., \& Fachrezy, F. (2020). Analisis kondisi fisik menggunakan software kinovea pada atlet taekwondo dojang mahameru surakarta. Transformasi: Jurnal Pengabdian Masyarakat, 16(2), 133-144. https://doi.org/10.20414/transformasi.v16i2.2635

Ngadiman. (2011). Pengembangan alat bantu untuk latihan footwork bulutangkis berbasis teknologi microcontroller. In Jurnal Iptek Olahraga (Vol. 13, pp. 146-165).

Nurkholis. (2017). Goal setting: pendampingan pada atlet panahan pplp jawa timur. Indonesia Performance Journal, 1(2), 119-124.

Permatasari, N. K. Ni., Rusdiana, A., \& Ruhayati, Y. (2016). Pengembangan alat ukur waktu reaksi berbasis microcontroller. Jurnal Terapan Ilmu Keolahragaan, 1(2), 13. https://doi.org/10.17509/jtikor.v1i2.1584

Purnama, S. (2013). Produk pembelajaran bahasa arab sigit purnama. Literasi, 4(1), 19-32.

Puspitaningayu, P. ., Widodo, A. ., \& Yundra, E. . (2018). Wireless body area networks dan pengaruhnya dalam perkembangan teknologi m-health. INAJEEE : Indonesian Journal of $\begin{array}{llll}\text { Electrical and } \quad \text { Eletronics } & \text { Engineering, } & 1(1), & \end{array}$ https://doi.org/10.26740/inajeee.v1n1.p24-30

Puspitasari, P. W., RIZKY, M. Y., \& BEKTI, R. A. (2020). Analisis tingkat kebugaran jasmani dan status gizi pada atlet puslatkot kediri cabang olahraga terukur unggulan menuju porprov vii tahun 2021 dalam masa pandemi covid-19. Doctoral Dissertation, Universitas Nusantara PGRI Kediri, 1(1), 36-41.

Rahmat, R., Rusdiana, A., Supriyatna, A., Indonesia, U. P., Setiabudhi, J., \& Bandung, N. (2016). Pengembangan alat ukur kecepatan lari. Jurnal Terapan Ilmu Keolahragaan, 01(01), 3439.

Santosa, T. (2016). Pengembangan alat bantu return board untuk forehand topspin tenis teja. Jurnal Pedagogik Olahraga, 2(2), 30-48. 
Saputra, S., \& Ihsan, N. (2020). Digital based sit-up test instrument development. The 2nd International Conference on Research and Learning of Physics, 1481(1). https://doi.org/10.1088/1742-6596/1481/1/012032

Sugiyono. (2011). Metode penelitian kuantitatif, kualitatif dan $r \& d$. Bandung : CV AlFABETA.

Sumadi. (2013). Metodologi Penelitian. Jakarta : Rajawali Press.

Syafruddin. (2011). Ilmu kepelatihan olahraga, teori dan aplikasinya dalam pembinaan olahraga. Padang: UNP Press.

Syakur, M. A., Badruzaman, , \& Paramitha, S. T. (2017). Pengembangan alat bantu latihan pelontar bola futsal berbasis mikrokontroler dengan menggunakan software pemograman arduino. Jurnal Terapan Ilmu Keolahragaan, 2(1), 29. https://doi.org/10.17509/jtikor.v2i1.4963

Undang-Undang Republik Indonesia Nomor 3 Tahun 2005 \& Peraturan Pemerintah Republik Indonesia. Sistem Keolahragaan Nasional. (2007). Bandung : Citra Umbara.

Yuberti. (2014). Penelitian dan pengembangan yang belum diminati dan perspektifnya. Jurnal Ilmiah Pendidikan Fisika Al-Biruni, 3(2), 1-15.

Yusup, F. (2018). Uji validitas dan reliabilitas instrumen penelitian kuantitatif. Jurnal Tarbiyah: Jurnal Ilmiah Kependidikan, 7(1), 17-23. https://doi.org/10.18592/tarbiyah.v7i1.2100

Zafar Sidik, D. (2017). Mengajar dan melatih atletik. Bandung : PT Remaja Rosdakarya. 